\title{
Atividades rítmicas e Educação Física escolar: possíveis contribuições ao desenvolvimento motor de escolares de 08 anos de idade
}

\author{
Tatiane Aparecida Rondon ${ }^{1}$ \\ Vera Lícia de Souza Baruki ${ }^{2}$ \\ Keli Roberta Ávila da Cruz ${ }^{1}$ \\ Fabiane de Oliveira Macedo ${ }^{2}$ \\ ${ }^{1}$ UNIDERP Universidade para o Desenvolvimento do Estado e da Região do Pantanal, \\ Campo Grande, MS, Brasil \\ 2 Universidade Católica Dom Bosco, Campo Grande, MS, Brasil
}

\begin{abstract}
Resumo: No desenvolvimento infantil, as atividades motoras são de real importância para as relações interpessoais, proprioceptivas e ambientais. Considerando que o ensino de atividades rítmicas no ambiente escolar pode contribuir na ampliação da comunicação e apreensão do mundo por parte do aluno, ajudando a desenvolver melhor sua percepção espaço-temporal e paralelamente, a imagem corporal, esta pesquisa teve como objetivo avaliar as contribuições de um programa de atividades rítmicas para o desenvolvimento motor no que se refere às variáveis equilíbrio, esquema corporal, Idade Motora Geral, Quociente Motor Geral e Idade Cronológica. Todas as variáveis apresentaram melhoras significativas, porém a maior significância apresentada foi do equilíbrio. Portanto o programa de atividades rítmicas é aplicável ao ambiente escolar e pode conferir contribuições ao desenvolvimento de escolares.
\end{abstract}

Palavras-chave: Equilíbrio. Esquema corporal. Atividades Rítmicas. Escola.

\section{Rhythmics activities and physical education at school: possible contributions to motor development of student's school at 08 years old}

\begin{abstract}
In child development, motor activities are of real importance to interpersonal relations, proprioceptive and environmental. Whereas the teaching of rhythmic activities in the school environment can contribute to more effective communication and apprehension of the world by students, helping to develop better perception and spatial-temporal parallel body image, this study was to evaluate the contributions of a program of rhythmic activities for motor development in relation to the variables balance, body scheme, General Motor Age, Motor Quotient General and Chronological Age. All variables showed significant improvements, but most significant was made to balance. So the program of rhythmic activities apply to the school environment and can give contributions to the development of students.
\end{abstract}

Key Words: Balance. Human body. Rhythmic activities. School.

\section{Introdução}

No caderno de Educação Física, dos PCNs (1997) a dança está inserida dentro de um bloco de conteúdos denominado Atividades Rítmicas e Expressivas, que segundo Barreto (2004) deve ser articulado aos conteúdos do corpo, esporte, lutas e ginásticas.

Esse bloco de conteúdos deverá contemplar as manifestações da cultura corporal que têm como características comuns a intenção de expressão e comunicação mediante gestos e a presença de estímulos sonoros como referência para o movimento corporal. Trata-se das danças e brincadeiras cantadas. (BRASIL, 1997)

Para o Conselho Nacional de Educação- CNE (2009) a Educação Física é uma ciência com enfoque no estudo e intervenção do movimento humano, com base nas diversas manifestações da atividade física, onde estão inseridas as ginásticas, jogos e esportes nas dimensões sociais participação, educação, saúde e competição.

Apesar da resolução do CNE e dos blocos de conteúdos para Educação Física Escolar dos Parâmetros Curriculares Nacionais (PCNs), esse conteúdo não parece ser uma realidade na escola pública que foi campo de estudo desta pesquisa, onde era renegado às atividades folclóricas e tradicionais festas juninas. Esta percepção relacionada em particular a dança é compartilhada por Fiamoncini (2003), Ehrenberg e Gallardo (2005) e Assis et.al (2009) ao afirmarem que quando esta é oferecida aos educandos objetiva movimentos mecanizados e pré determinados, o que é comum em datas 
comemorativas, e festas juninas, sendo assim concebida como produto final e não como processo e sua importância.

De acordo com Tibeau (2006), outro fato a ser considerado em relação às atividades rítmicas é que as mesmas estão atreladas ao aparente preconceito em relação às atividades que utilizam música, expressão de sentimentos, emoções e criatividade de movimento, por parte dos profissionais de Educação Física Escolar, que se utilizam do discurso de que não foram preparados na graduação para exercerem tal atividade, e a partir deste argumento acabam por privilegiar os esportes para alcançar seus objetivos.

De acordo com Marques (1997) "na maioria dos casos, os professores não sabem exatamente o que, como ou até mesmo porque ensinar dança na escola", porém, Nanni (2005) exprobra esta idéia ao afirmar que a nova tendência da atividade rítmica e nela a dança converge para o movimento humano expressivo sendo assim passível de ser integrada ao currículo escolar.

No desenvolvimento infantil, as atividades motoras são de real importância para as relações interpessoais, proprioceptivas, ambientais. Assim o processo de ensino e aprendizagem por meio das atividades rítmicas deve-se apresentar como intermédio entre o saber, corpo e movimento. Para Strazzacappa (2001) o movimento corporal possibilita ao indivíduo sentir o mundo, e por ele ser sentido.

Perez Galhardo (2002) postulam que as atividades rítmicas inseridas nas aulas de Educação Física não ultrapassem o âmbito da vivência, proporcionando aos alunos que experimentem e apropriem-se desta possibilidade de manifestação corporal. Assim, o interesse pedagógico não deve estar centrado predominantemente no domínio técnico do conhecimento trabalhado, mas sim na possibilidade de incorporação das muitas técnicas de execução que possibilitem a sua transferência para várias outras situações ou contextos. Fiamoncini (2003) considera que, embora esses conteúdos sejam muito importantes, não devem ser reduzidos a priorização da técnica ou algum estilo.

Nanni (2002) afirma que a escola deverá relacionar conteúdos significativos e que tenham relação com a vida dos educandos permitindo a compreensão das coisas que a cercam e suas relações.

Considerando a realidade da Educação Física Escolar na escola apresentada, a proposta desta pesquisa foi intervir com um programa de atividades rítmicas que atendesse dois requisitos condizentes a faixa etária em estudo: oferecer atividades rítmicas partindo das experiências motoras que os escolares traziam consigo e apresentar atividades rítmicas sem priorizar a técnica passando pela descoberta e experimentação.

Para Fornel et.al (2006) o ensino de atividades rítmicas no ambiente escolar pode contribuir na ampliação da comunicação e apreensão do mundo por parte do aluno a medida que formas e sons passam gradativamente a compor 0 universo sensório-motor destes ajudando a desenvolver melhor sua percepção espaçotemporal e paralelamente, a imagem corporal.

Mattos e Neira (2003) apontam outros benefícios que essas atividades podem proporcionar aos educandos tais como: descoberta do próprio corpo, novos movimentos e limites do mesmo, melhora da coordenação motora, aspectos considerados pelos autores como importantes para o desenvolvimento corporal posterior.

Partindo do pressuposto de que as atividades rítmicas podem contribuir no sentido de oferecer uma ampla variedade de experiências motoras favorecendo o desenvolvimento motor, surgiu a seguinte questão: de que forma um programa de atividades rítmicas estruturado e orientado aos alunos com oito anos de idade pode contribuir no desenvolvimento motor?

Partindo desta questão este estudo tem como objetivo avaliar os resultados oriundos da aplicação de um programa de atividades rítmicas no que se refere ao desenvolvimento motor nas variáveis: equilíbrio, esquema corporal, Idade Motora Geral, Quociente Motor e Idade Cronológica em escolares com oito anos de idade.

No que se refere ao desenvolvimento motor, faz-se necessária a definição de alguns termos e conceitos que serão utilizados no decorrer desta pesquisa sendo assim, alguns autores desta temática serão referenciados.

As atividades motoras começam ainda na gravidez onde o feto já se movimenta. Após o nascimento, pode se perceber claramente sua evolução motora ao buscar sua interação com o mundo, posteriormente a criança passa por mudanças maturativas diárias e surpreendentes em função da satisfação das necessidades que o meio suscita. Para Rosa Neto (2002) à medida que a criança cresce em um mundo de objetos e dos demais do qual depende estritamente, ela 
percebe este mundo através de seu corpo, ao mesmo tempo em que seu corpo se relaciona com o mundo exterior.

De acordo com Gesell (1992), o movimento assume uma importância vital como elemento de construção da personalidade e do desenvolvimento motor da criança, resultando por um lado das experiências vividas e, por outro, da maturação fisiológica.

Gallahue e Ozmun (2003) postulam que "o desenvolvimento motor é um processo evolutivo, que possui porta aberta para os fatores do meio ambiente, conjugado com os fatores internos", considerando que o desenvolvimento motor é imbricado às vivências motoras, Paim (2003) afirma que quanto maior o número de experiências motoras maior será o desempenho nas tarefas motoras realizadas.

O desenvolvimento motor, segundo Haywood e Getchell (2004) é considerado um processo seqüencial, contínuo e relacionado à idade cronológica, pelo qual o ser humano adquire uma enorme quantidade de habilidades motoras, as quais progridem de movimentos simples e desorganizados para a execução de habilidades motoras altamente organizadas e complexas.

A fim de que ocorra uma boa evolução motora, Pellegrini et.al (2006) afirmam que é necessário que as restrições do ambiente sejam elas orgânicas, ambientais e de tarefa sejam evitadas. Dentre as restrições ambientais (ambiente físico e social) encontram-se as variáveis força gravitacional; disponibilidade de ambiente adequado para uma prática desportiva; temperatura; falta de acesso aos meios de comunicação. Já as restrições orgânicas (características físicas e funcionais do organismo) são capacidade de percepção e cognição; força; resistência; preferência manual, enquanto as restrições de tarefa (relação com um objetivo) referem-se a acompanhamento de uma música com palmas; distância de um arremesso de algum objeto; o uso da letra cursiva ou de forma.

Dentre os elementos básicos do desenvolvimento motor encontra-se o esquema corporal que Schilder (1999), denomina como modelo postural do corpo ou a imagem tridimensional que os sujeitos têm do corpo, como o percebem mesmo que a informação não tenha chegado através dos sentidos. Segundo Le Boulch (1990, p. 15), "a imagem do corpo não está pré-formada, ela é "estrutura estruturada" e através das relações mútuas do organismo e do meio a imagem do corpo organiza-se como núcleo central da personalidade.
Para Barreto (2002) o esquema corporal se estrutura sobre a base dos componentes neurológicos em desenvolvimento e maturação onde se liga fundamentalmente, as percepções exteroceptivas, proprioceptivas e interoceptivas que permitem estabelecer, em um momento inicial a consciência sobre localização espacial total, a capacidade e o funcionamento de uma determinada parte do corpo, a consciência inicial sobre a magnitude do esforço necessário para realizar uma determinada ação, e a consciência sobre a posição do corpo e suas partes no espaço durante esta ação.

Assim como o esquema corporal, o equilíbrio refere-se a outro componente do desenvolvimento motor considerado necessário para as funções cotidianas e evidenciado nas atividades rítmicas.

Guyton (1992) considera que para a manutenção do equilíbrio corporal estático é necessário que um conjunto de estruturas funcione de maneira harmoniosa e fazem parte desta estrutura: o sistema vestibular, os olhos e o sistema proprioceptivo. A manutenção do equilíbrio geral é realizada pelo sistema vestibular, que detecta as sensações de desequilíbrio e é composto de um sistema de tubos ósseos e câmaras na porção petrosa do osso temporal chamado de labirinto ósseo e dentro dele um sistema de tubos membranosos e câmaras chamadas de labirinto membranoso (ou membranáceo), que é a parte funcional do sistema vestibular.

As informações proprioceptivas também são importantes na manutenção do equilíbrio corporal, segundo Ganong (1998) a orientação do corpo no espaço também depende de impulsos de proprioceptores nas cápsulas das articulações, que enviam dados sobre a posição relativa das várias partes do corpo e impulsos de exteroceptores cutâneos, especialmente os de tato e pressão. Pode se deferir que quanto mais informações exteroceptivas forem oferecidas, maior será a adaptação do organismo resultando em mais equilíbrio.

\section{Procedimentos Metodológicos}

Há a necessidade de registrar algumas limitações da pesquisa como a aplicação do programa de atividades rítmicas em uma única escola e a não aplicação de um teste piloto, no entanto as demais providências quanto ao registro das informações e ao programa serão relatadas na metodologia que se segue.

Este estudo originou-se a partir do estágio curricular obrigatório do curso de Educação 
Física com alunos do $3^{\circ}$ ano do Ensino Fundamental com oito anos de idade da escola Municipal Professor Vanderlei Rosa, em Campo Grande, MS.

A amostra foi selecionada de forma aleatória e teve como critério de exclusão alunos que já participavam de algum grupo ou projeto com atividades rítmicas. Fizeram parte deste estudo 16 escolares, sendo 7 meninos e 9 meninas.

A pesquisa caracterizou-se como um estudo descritivo de corte transversal com abordagem quantitativa.

O instrumento utilizado foi a Escala de Desenvolvimento Motor-EDM (ROSA NETO, 2002) a fim de avaliar os aspectos do desenvolvimento motor no pré e pós- teste. A EDM é de aplicação individual, com duração média de 30 a 45 minutos, permitindo a classificação do desenvolvimento motor desde o nível "Muito Inferior" até "Muito Superior", traçando um perfil motor que abrange as seguintes áreas: motricidade fina, coordenação global, equilíbrio, esquema corporal, organização espacial e temporal.

A EDM compreende tarefas específicas para cada faixa etária (2 a 11 anos) em cada elemento da motricidade. A complexidade da tarefa a ser realizada aumenta de acordo com o aumento da idade. Os participantes foram avaliados a partir do teste correspondente à sua idade cronológica em cada elemento da motricidade, e terminavam a avaliação quando não desempenhavam corretamente a tarefa proposta. A idade correspondente à última tarefa desempenhada corretamente pela criança caracteriza-se por idade motora de cada variável. Comparando-se a idade cronológica e a idade motora pode-se determinar o avanço ou atraso motor da criança.

Embora a Escala de Desenvolvimento Motor contenha as provas de motricidade fina, coordenação global, equilíbrio, esquema corporal, organização espacial e temporal que são considerados por Rosa Neto (2002) como elementos básicos da motricidade, e que os escolares foram avaliados em todas as provas, neste estudo serão analisadas e discutidas apenas as variáveis relacionadas ao equilíbrio, esquema corporal, IMG, IC e QM.

A Idade Motora Geral é obtida da seguinte maneira:

$$
\text { IMG: IM1+ IM2+IM3+ IM3+ IM5+ IM6/6 }
$$

Já o quociente motor é calculado a partir da Idade Motora Geral dividida pela Idade cronológica e multiplicado por 100. QM = IMG/IC $\times 100$

Os materiais utilizados foram: folha de resposta de apontamento de dados, folhas complementares (para os testes onde houve necessidade), materiais auxiliares (para a execução dos testes), ficha de observação sobre as atividades desenvolvidas, aparelho e amplificadores de som e CDs de vários estilos musicais.

A aplicação dos testes ocorreu da seguinte maneira: inicialmente foi realizada uma bateria motora de testes denominada de pré-teste, com seis provas motoras a fim de mensurar a idade motora de cada variável (equilíbrio, motricidade fina, coordenação global, esquema corporal, percepção espacial e percepção temporal) cujo resultado foi registrado na folha de resposta com - símbolo 1 para positivo e 0 para negativo. Neste caso o 1 representa a maneira totalmente correta preconizada pelo teste, 0 a maneira totalmente incorreta e $1 / 2$ parcialmente correta. Para os testes que exigiam habilidade com o lado direito e esquerdo foi atribuído o valor de $1 / 2$ para cada lado com êxito. $O$ valor máximo que poderia ser alcançado em cada prova motora é de 10 pontos.

Abaixo será exposta uma breve descrição das provas motoras realizadas pelos escolares em cada variável:

- Motricidade fina: Com a ponta do polegar tocar com a máxima velocidade os dedos da mão, um após o outro, sem repetir a seqüência.

- Motricidade global - Saltar uma fita elástica na altura de $40 \mathrm{~cm}$.

- Equilíbrio - Equilíbrio com o tronco flexionado sobre as pontas dos pés.

- Esquema corporal - prova de rapidez (marcar o máximo de riscos dentro uma folha quadriculada, quadrado por quadrado);

- Organização espacial - Reconhecimento sobre o outro: "toque minha mão direita", "toque minha mão esquerda", "em que mão está a bola?".

Após o pré-teste foi iniciado com os alunos o programa de Atividades Rítmicas elaborado pelas pesquisadoras considerando os seguintes aspectos: faixa etária dos alunos, os materiais disponíveis na escola e a turma composta por meninos e meninas. As Atividades Rítmicas elaboradas apoiaram-se nos conceitos de Perez e Galhardo (2002) no que concerne às experiências e vivências corporais por meio das atividades rítmicas em detrimento a técnica. A metodologia adotada durante as aulas considerou a idade dos alunos e optou-se por trabalhar as Atividades Rítmicas de maneira lúdica. 
A intervenção ocorreu durante 18 aulas, com dois encontros semanais, cada um com duração de 50 minutos. As aulas com Atividades Rítmicas ocorreram no horário das aulas de Educação Física no pátio da escola, na quadra ou na sala de aula.

As atividades realizadas durante o período de intervenção foram: equilíbrio onde os alunos competiam entre si ("quem consegue caminhar sobre uma pequena mureta, ou quem sabe permanecer nela com apenas um dos pés?" Ou "quem sabe dançar a música utilizando movimentos de saltos e aterrissagens seguidas da busca do equilíbrio?" ou ainda "quem consegue permanecer até uma parte determinada da música em alguma pose de equilíbrio estático?" "estátua!"), jogos computadorizados para identificar os lados direito e esquerdo cujo referencial foi o corpinho de um boneco, escravos de Jó, foi confeccionado um "palco" delimitado com fita crepe um espaço retangular na quadra e dito aos alunos que ali seriam realizadas as "apresentações", mas, ninguém poderia ficar fora dele, pois correria o risco de cair no "chão", e também ninguém poderia ficar muito próximo do colega, pois assim quem estivesse atrás poderia não ser visto pelo "público".

Foi dado aos alunos um barbante e todos tiveram que amarrar no punho direito, e foram feitas várias perguntas como: -"Quem está do seu lado direito? Quem esta na sua frente? Quem está do lado esquerdo do colega...?" assim com a orientação do barbante todos responderam as perguntas de forma positiva, muitos nem quiseram desamarrar o barbante no final da aula. Amarelinha, pular corda cantando músicas do cotidiano dos escolares.

Para FREIRE (2003, p.24) "a adoção de atividades da cultura infantil como conteúdo pedagógico facilita o trabalho de professores, pois garante 0 interesse e a motivação das crianças." Além disso, por meio da brincadeira a criança envolve-se no jogo, relações são estabelecidas e a criança tem oportunidade de desenvolver capacidades como atenção, afetividade e outras habilidades perceptuais psicomotoras.

Após as dezoito aulas os alunos foram reavaliados pelas provas motoras. $O$ presente estudo atendeu as diretrizes e normas regulamentadoras de pesquisa envolvendo seres humanos, de acordo com a resolução $\mathrm{n}^{\circ} 196$ de 10 de outubro de 1996, do Conselho Nacional de Saúde.

\section{Resultados e Discussão}

A bateria de testes proposta por Rosa Neto deve ser aplicada em sua totalidade e assim foi feito, porém serão apresentados apenas os resultados das variáveis: equilíbrio, esquema corporal, Idade Motora Geral (IMG), Coeficiente motor geral (QMG) e idade cronológica (IC).

O quadro abaixo apresenta o teste estatístico calculado a partir da diferença da média de cada variável após e antes a intervenção.

Quadro 1. Test Statistics

\begin{tabular}{|c|c|c|c|c|c|}
\hline Variáveis avaliadas & EQUIL2- EQUIL1 & $\mathrm{EC} 2-\mathrm{EC} 1$ & IMG2 - IMG1 & $\mathrm{IC} 2-\mathrm{IC} 1$ & QM2 - QM1 \\
\hline $\begin{array}{l}\text { Diferença da media de cada variável após e antes a } \\
\text { intervenção }\end{array}$ & $-2,855$ & $-3,426$ & $-3,519$ & $-3,873$ & $-3,466$ \\
\hline Asymp. Sig. (2-tailed) & ,004 & 001 & 000 & 000 & 001 \\
\hline
\end{tabular}

a Based on negative ranks. b Wilcoxon Signed Ranks. Test $p \leq 0,05$

De acordo com os valores de cada variável, pode-se deferir que não houve significância para IMG (Idade Motora Geral) e IC (Idade Cronológica). Já as variáveis esquema corporal (EC) e coeficiente motor (QM) apresentaram significância de 0,001 .Os dados que mais apresentaram significância foram os de EQUIL que demonstraram valores de 0,004 , o que denota maior variação após a intervenção. $\mathrm{Na}$ totalidade houve significância de $p \leq 0,05$.

As variáveis provenientes das provas motoras de equilíbrio e esquema corporal foram as que apresentaram resultados mais significativos na relação pré e pós intervenção. No entanto podemos observar que a variável esquema corporal $($ pré $=70$ e pós $=100$ ) se comparada com o equilíbrio (pré $=105$ e pós $=120$ ) antes e depois da intervenção de atividades rítmicas apresenta um resultado consideravelmente maior. Os resultados da IMG, IC e QMG também apresentaram variação após a intervenção sendo que entre eles a IMG corresponde ao valor maior no gráfico.

Estes resultados podem estar relacionados à participação motivada dos alunos referente às atividades propostas, pois desde o início as provas motoras foram muito bem recebidas por eles. As atividades propostas faziam parte das brincadeiras dos alunos, e que por este motivo descaracterizava qualquer tipo de avaliação ou "prova". 
Figura 1. Média Geral das variáveis pesquisadas na pré e pós prova motora

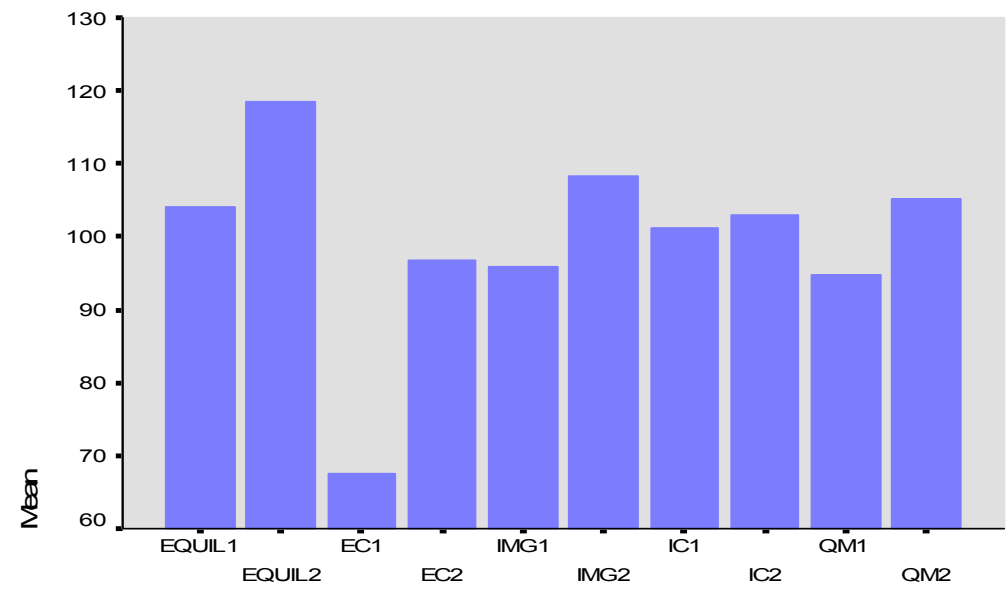

Figura 1: Valores de significância referentes a: equilíbrio 1 e 2: pré e pós-prova, esquema corporal 1 e 2 : pré e pós-prova, idade motora geral 1 e 2: pré e pós-prova idade cronológica 1 e 2: pré e pós-prova e quociente motor gera I1 e 2: pré e pós-prova.

Obs: QM deverá ser lido e entendido como QMG (quociente Motor Geral)

A adoção de atividades da cultura infantil como conteúdo pedagógico conforme FREIRE (2003) garante o interesse e a motivação das crianças, e associadas às diferentes experiências motoras proporcionadas pelas atividades rítmicas como deslocamentos variados, equilíbrio dinâmico, equilíbrio estático, ritmo apresentadas aos escolares por meio de "brincadeiras" como estátua, corrida de saci pererê, caminhar sobre a estreita ponte e escravos de Jó entre outros, os motivaram, e mais que isso, desmitificou as questões de gênero que estavam presentes nas aulas e entrelaçadas às atividades rítmicas.

$\mathrm{Na}$ figura 2 foram comparadas as médias do equilíbrio apresentado pelos alunos pré e pós-prova.

Figura 2. Comparação das Médias de Equilíbrio pré e pós-prova motora

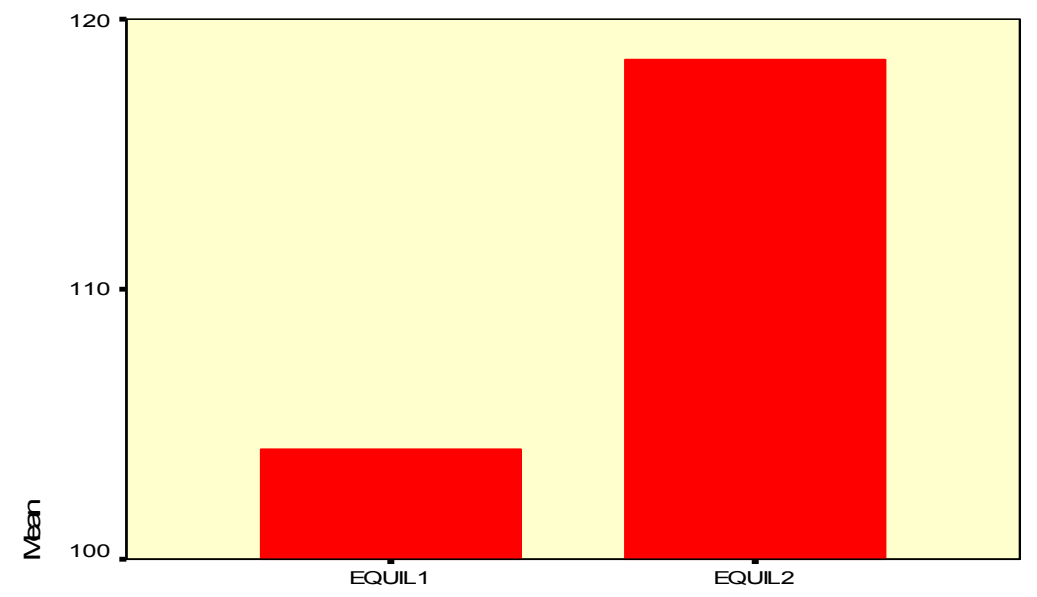

Guimarães (2005) define o equilíbrio como a interação entre grupos musculares que controlam o corpo sobre sua base, variando de acordo com a posição em que a pessoa se encontra. Assim, quando nos locomovemos ocorre uma compensação do corpo numa tentativa de ajuste do equilíbrio, quando outros estímulos exteroceptivos são oferecidos essas compensações são evidenciadas, pois necessitamos de mudanças de nível e direção.

As atividades rítmicas propostas pelo programa contribuíram no equilíbrio à medida que estimularam atitudes posições ou posturas que provocaram a necessidade de adaptação do corpo a fim de alcançar o equilíbrio. Importante é ressaltar que estas atividades ocorridas durante a intervenção foram conduzidas de forma desafiadora com os alunos questionando-os da seguinte forma: quem ficava mais tempo na posição de "avião"? Ou quem consegue permanecer imóvel nas atividades de estátua?

Pode se acrescentar às adaptações necessárias durante as atividades 0 que Gonçalves et.al apresentam como limites da estabilidade que compreendem as áreas 
envolvidas pelas bordas externas dos pés, em contato com o chão, estes limites não são fixos e mudam de acordo com a tarefa, a biomecânica individual e os diversos aspectos do ambiente resultando em adaptação, acomodação e equilíbrio.

Figura 3. Comparação das Médias do Esquema Corporal pré-e pós-prova

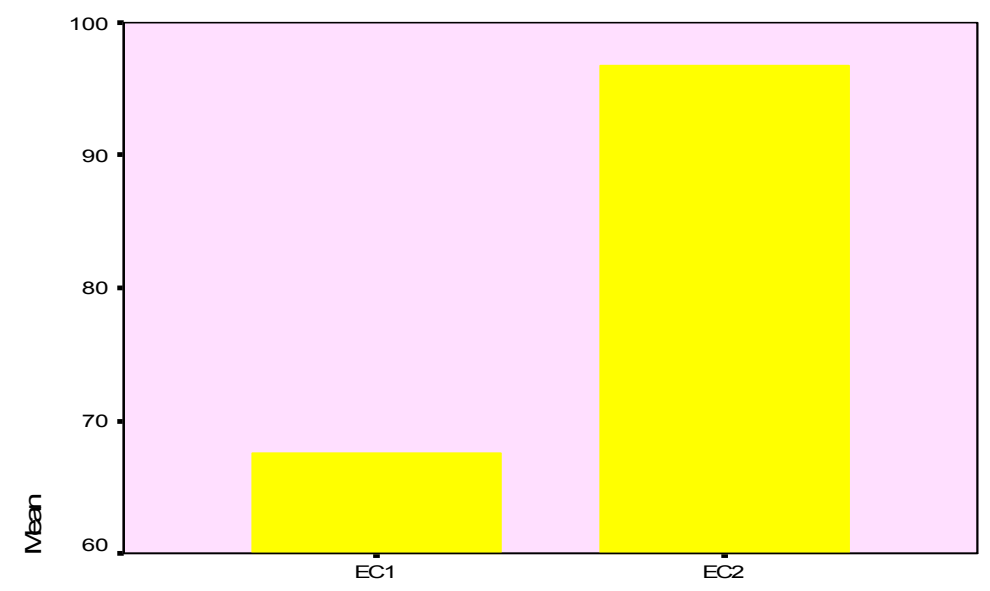

Le Boulch (1987) divide o esquema corporal em três etapas dentro da evolução psicomotora. A primeira é denominada "o corpo vivido" correspondente ao período sensório motor de Piaget, a partir dos três anos a criança experimenta a fase do "corpo percebido", nesta fase o esquema corporal esboça sinais de organização e a possibilidade de deslocar a atenção do meio para si. Já a terceira fase denominada "corpo representado"(7 aos 12 anos, ) corresponde ao período de operações concretas onde ocorre a representação mental do próprio corpo ao mesmo tempo do domínio da motricidade. Esta terceira fase corresponde exatamente à faixa etária do presente estudo. Sendo assim podemos considerar que as atividades rítmicas na idade dos escolares desta pesquisa são recomendadas, pois, podem oferecer estímulos a uma motricidade latente e auxiliar na representação corporal.

De acordo com Campos; Lima (1996) uma criança cuja imagem ou esquema corporal é mal definida, não coordena bem seus movimentos e, conseqüentemente, suas habilidades manuais são difíceis podendo ocorrer que a caligrafia seja feia e a leitura não seja harmoniosa no sentido em que a criança não segue o ritmo da mesma, ou para no meio da frase ou da palavra. Outro aspecto que chama atenção e pode estar relacionado ao esquema corporal é quando a criança não consegue reconstruir um boneco articulado que pode estar relacionado a uma defasagem na elaboração da consciência do seu corpo.

Figura 4. Comparação das Médias da Idade Motora Geral pré e pós- prova motora

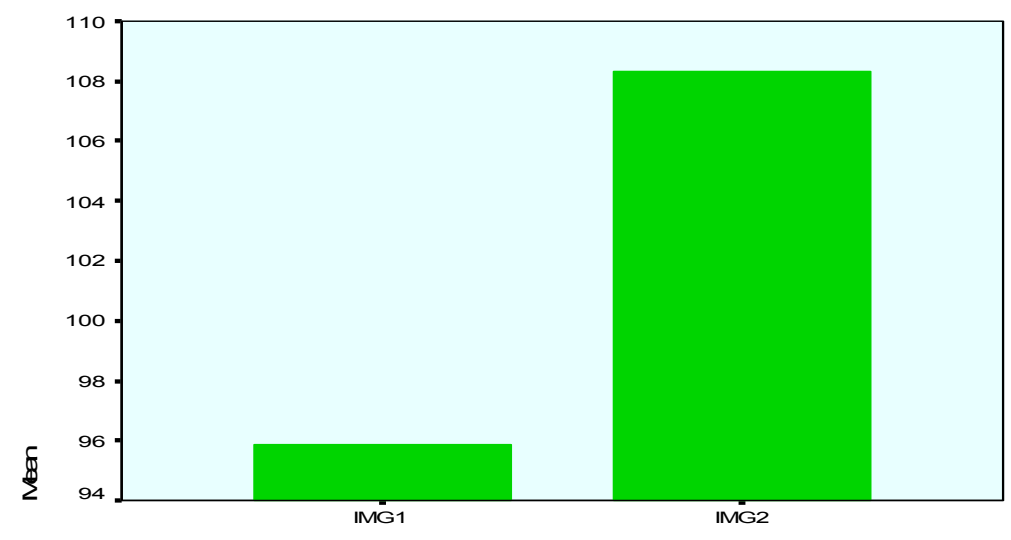

$\mathrm{Na} 2^{\mathrm{a}}$ bateria motora, foi percebido o melhor entendimento das provas a serem realizados e esse talvez tenha sido um dos motivos pelo qual ela foi realizada com mais facilidade em relação a sua primeira aplicação dispensando explicações detalhadas.

Cada prova motora era composta por uma série de provas destinadas a determinadas idades que se iniciam com 2 anos e estendem-se até aos 11 anos totalizando 60 provas. Neste estudo foram realizadas somente as provas referentes à idade de 8 anos, partindo do principio que os escolares participantes se encontravam neste nível motor, o que totalizou 42 provas realizadas concretamente.

Como a IMG é o somatório de todas as variáveis mensuradas pode se deferir que houve melhora nestas. 
Figura 5. Comparação das Médias da Idade Cronológica pré e pós-prova.

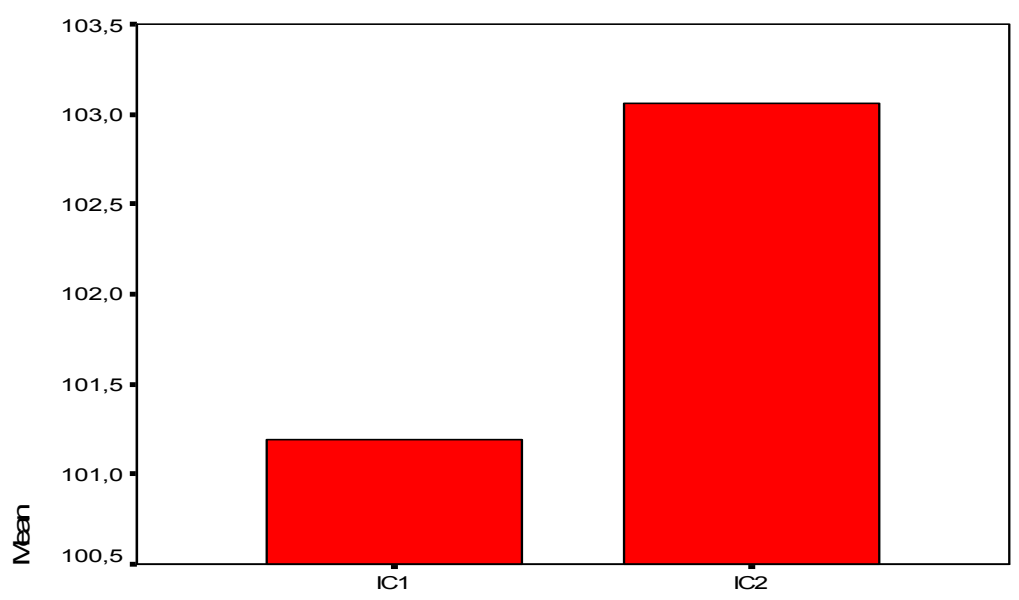

Houve um avanço na idade cronológica de cada aluno em função da data de realização da $1^{\text {a }}$ bateria de provas até a realização da $2^{a}$ bateria de provas que correspondeu a 2 meses (tempo de intervenção). Autores da área do desenvolvimento motor como Gallahue (2003) ao referir-se a idade e escala de tempo, consideram fundamental este período de tempo para o desenvolvimento, às vezes, de forma significativa no aspecto motor em crianças, outras vezes demonstrando atrasos em determinado aspecto do desenvolvimento. Segundo ele, cada indivíduo é peculiar com sua própria escala de tempo para o desenvolvimento que define como combinação da hereditariedade e influências ambientais. Barela (1997) afirma que o princípio do desenvolvimento humano constitui um sistema dinâmico com características não lineares e com capacidade de interação entre seus componentes proporcionando a emergência do comportamento. A não linearidade reside no fato de haver momentos de estabilidade e instabilidade no sistema e estes desencadearem uma mudança no comportamento exigindo maior interação dos componentes envolvidos.

Há que se considerar que com o aumento da IC os indivíduos são biologicamente capazes de realizar tarefas mais complexas e isto pode influir na IMG.

Figura 6. Comparação das Médias do Quociente Motor pré e pós-prova motora

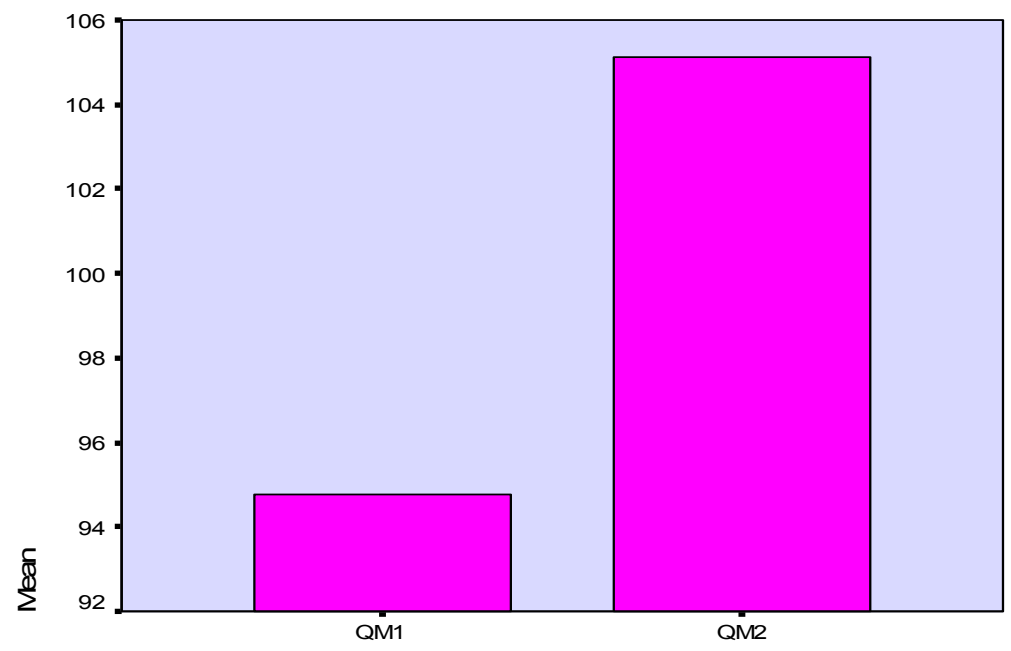

Mediante análise da figura acima observamos que houve um aumento na média entre QMG1 e QMG2 que nos fornece subsídios para classificar os alunos quanto a Escala de Desenvolvimento abaixo, pois o QMG apresenta o cálculo da diferença entre Idade Motora Geral avaliada pelas provas motoras e Idade Cronológica dos escolares.
Quadro 2. Escala de Desenvolvimento

\begin{tabular}{|l|l|l|}
\hline Escala de desenvolvimento & Pré-teste & Pós-teste \\
\hline Muito superior & - & - \\
\hline Superior & - & 01 aluno \\
\hline Normal alto & 01 aluno & 03 alunos \\
\hline Normal médio & 12 alunos & 11 alunos \\
\hline
\end{tabular}




\begin{tabular}{|l|l|l|}
\hline Normal baixo & 02 alunos & - \\
\hline Inferior & - & 01 aluno \\
\hline Muito inferior & 01 aluno & - \\
\hline
\end{tabular}

Quadro 2: Muito superior - representa a IMG 30 ou mais meses acima da IC; Superior - representa a IMG 20 a 29 meses acima da IC; Normal alto - representa a IMG 10 a 19 meses acima da IC; Normal média representa a IMG igual a IC; Normal baixo - representa a IMG 10 a 19 meses abaixo da IC; Inferior representa a IMG 20 a 29 meses abaixo da IC; Muito inferior - representa 30 meses ou mais abaixo da IC.

A maioria dos escolares permaneceu na escala de desenvolvimento considerada por Rosa Neto (2002) como normal médio, ou seja, com Idade Motora Geral igual à Idade Cronológica. No entanto, houve um escolar que partiu da escala muito inferior para a escala inferior e dois escolares que apresentaram uma progressão transferindo-se da escala de desenvolvimento normal baixo para a escala normal alto e outro escolar que se transferiu da escala de desenvolvimento normal alto para a escala superior. Analisando o quadro perceberemos também que houve alteração na escala de um escolar que se encontrava no normal médio e passou para a escala normal superior. Estes cinco escolares que não pertencem ao grupo com IMG igual a IC neste estudo, vem de encontro ao pensamento de Pellegrini et.al (2006) ao afirmam que é necessário que as restrições do ambiente sejam elas orgânicas, ambientais e de tarefa sejam evitadas, entendidas neste estudo como ambientais a escola, o professor e os alunos e as de tarefas o programa de atividades rítmicas desenvolvido e aplicado.

\section{Considerações Finais}

As atividades rítmicas podem conferir contribuições no desenvolvimento motor, especialmente nos anos iniciais do ensino fundamental, onde as habilidades mais importantes estão sendo consolidadas. Dentro desta perspectiva, de habilidades motoras, a Educação Física, entre outros papéis, tem o de alargar a fronteira destas habilidades.

Através deste estudo realizado em uma escola foi possível desenvolver um programa de atividades rítmicas e avaliar a contribuição no desenvolvimento motor dos escolares selecionados.

A partir do programa desenvolvido e da aplicação da Escala de Desenvolvimento Motor de Rosa Neto (2002) alguns pontos podem ser destacados deste estudo.

Primeiramente percebe-se a possibilidade de aplicar as atividades rítmicas no ambiente escolar, porém sua aplicabilidade está vinculada à metodologia e forma como é apresentada aos alunos. Nesta mesma perspectiva encontra-se o trabalho que pode ser desenvolvido quando o objetivo é trabalhar o equilíbrio e o esquema corporal cuja importância é enfatizada na revisão literária para o desenvolvimento motor da criança.

Diante deste trabalho os resultados apresentados quanto ao estudo das variáveis equilíbrio e esquema corporal houve uma diferença entre os resultados apresentados antes da intervenção e a avaliação realizada após a realização das atividades rítmicas. Da mesma forma ocorreu com a variável esquema corporal. O resultado após a intervenção do programa com as atividades rítmicas foi superior ao valor apresentado antes da aplicação do programa.

$\mathrm{Na}$ Escala de desenvolvimento motor os escolares em geral permaneceram na escala de desenvolvimento normal médio o que reflete a limitação do estudo no que concerne ao tempo correspondente a aplicação da $1^{\text {a }}$ bateria de provas e $2^{a}$ bateria de provas. É importante também ressaltar que o escolar que passou da escala de muito inferior para a escala de inferior encontra-se ainda com a IMG abaixo da IC e merece ser acompanhado nas atividades escolares em geral.

Este estudo é uma iniciativa a mais dentro das atividades rítmicas, porque partimos do pressuposto que o conhecimento é construído diariamente baseado em questionamentos, em estudos realizados a partir de uma situação empírica. Dentro desta idéia este estudo dentro de suas limitações de realização e população, registra resultados e propostas de atividades rítmicas associadas ao desenvolvimento que podem ser relacionadas as questões socioeconômicas, a relação entre escolas estaduais e particulares que trabalham com a dança, enfim uma série de estudos que poderão contribuir para área da Educação Física.

\section{Referências}

ASSIS, M. D. P. et.al. Dança na escola: um estudo a partir do discurso dos envolvidos. Movimento \& Percepção, Espírito Santo do Pinhal, v. 10, n. 14, p. 297-318, jan./jun. 2009.

BARELA, J.A. Perspectiva dos sistemas dinâmicos: teoria e aplicação no estudo de desenvolvimento motor. In: PELLEGRINI, A.M. (Org.) Coletânea de Estudos: Comportamento Motor I. São Paulo: Movimento, 1997. p.11-28.

BARRETO, D. Dança... Ensino, sentidos e possibilidades na escola. São Paulo: Autores Associados, 2004. 
BARRETO, J.F. Sistema estomatognático y esquema corporal. Disponível em:

http://www.colombiamedica.univalle.edu.co/Vol30 No4/estomato.html.

BRASIL - MINISTÉRIO DA EDUCAÇÃO E CULTURA. Secretaria de Educação

Fundamental. Parâmetros Curriculares

Nacionais. Educação física Brasília: MEC/ SEF, 1997. 15p./96p.

BRASIL. Lei de Diretrizes e Bases da

Educação Nacional. Governo do estado de São Paulo, Lei 9.394, Editora do Brasil S/A, 1998.

CONSELHO NACIONAL DE EDUCAÇÃO. Diretrizes curriculares para graduação em Educação Física. Disponível em: www.confef.org.br.

EHRENBERG, M.C. GALLARDO, J.S.P. Dança: conhecimento a ser tratado nas aulas de Educação Física Escolar. Revista Motriz, v.11 n. 2, 2005.

FIAMONCINI, L. Dança na Educação: a busca de elementos na arte e na estética. Pensar a Prática, Vol. 6, 2003.

FORNEL, A. J. FERNANDES. Atividades Rítmicas desenvolvidas nas escolas da rede pública e particular dos municípios de Ji-paraná e Ouro Preto do Oeste (RO). Ciência e

Consciência - Revista Ulbra, Vol 1, 2006.

FREIRE, J. B. Educação como prática corporal. São Paulo: Scipione, 2003

GALLAHUE, D.L; OZMUN, J.C. Compreendendo o Desenvolvimento Motor. São Paulo: Phorte editora, 2003

GANONG, Willian F. Fisiologia Médica. Rio de Janeiro: Prentice-Hall do Brasil, 1998.

GESELL, A. A criança dos $\mathbf{0}$ aos $\mathbf{5}$ anos. São Paulo: Martins Fontes, 1992.

GONÇALVES, V.M.G et.al Avaliação do equilíbrio estático numa população de crianças deficientes auditivas. Arquivo de Neuro-Psiquiatria, v.51, n.3, p.346-351, 1993.

GUYTON, Arthur C. Tratado de fisiologia médica. Rio de Janeiro: Guanabara Koogan, 1992.

HAYWOOD KM, GETCHELL N. Desenvolvimento motor ao longo da vida. $3^{a}$ ed. Porto Alegre: Artmed, 2004, 344p.
LE BOULCH, Jean. O Desenvolvimento Psicomotor: do nascimento aos 6 anos. Traduzido por Ana Guardiola Brizolara. Porto Alegre, Artes Médicas, 1987.

MARQUES, I.A. Dançando na escola. Revista Motriz, v. 3, n. 1, p. 20-281997.

MATTOS,M.G; NEIRA,M.G. Educação Física Infantil: construindo o movimento na escola. Guarulhos, SP: Phorte Editora, 2004.

NANNI, D. Dança-Educação - pré-escola à universidade. Rio de Janeiro: 3a edição: 2002.

NANNI, D. Dança-educação: princípios, métodos e técnicas.Rio de Janeiro: Shape, 2005

PAIM, M. C. C. Desenvolvimento motor de crianças pré-escolares entre 5 e 6 anos. http://www.efdeportes.com/ Revista Digital. Buenos Aires - Año 8 - $n^{\circ} 58$ - Marzo de 2008.

PELLEGRINI, A. M. et al. O que o professor deve saber sobre o desenvolvimento motor de seus alunos. In: Alfabetização: assunto para pais e mestres. 1. Ed. Rio Claro: IB/UNESP, 1998.

PELLEGRINI, A. M. et.al. Comportamento Motor no Brasil: Um olhar para o passado, pensando no futuro. BRAZILIAN JOURNAL OF MOTOR BEHAVIOR, v. 1, p. 32-40, 2006.

PELLEGRINI, A. M. et al. Crianças com dificuldade de coordenação motora na periferia de uma cidade do interior de São Paulo.In: Anais do III Congresso Brasileiro de Comportamento Motor, UNESP,Rio Claro, 2006.

PEREZ GALLARDO, J.S. Educação Física: contribuições à formação profissional. ljuí: Unijuí, 2000.

ROSA NETO, F. Manual de avaliação motora. Porto Alegre: Artmed Editora, 2002.

SCHILDER, P. A. Imagem do Corpo: As Energias Construtivas da Psique. São Paulo: Martins Fontes, 1999.

STRAZZACAPPA, M. A educação e a fábrica de corpos: a dança na escola. Caderno Cedes. Vol. 21, n. 53. Campinas, Abril/2001.

TIBEAU,C. C. M. Motricidade e música: aspectos relevantes das atividades rítmicas como conteúdo da educação física. v.1, n.2, p.53-62, jun.2006 Universidade Bandeirante de São Paulo.

Trabalho originado no estágio curricular obrigatório na Universidade para o 
Desenvolvimento do Estado e da Região do

Pantanal - UNIDERP em 2007.

Esse artigo foi apresentado em Sessão Temática no VI Congresso Internacional de Educação Física e Motricidade Humana e XII Simpósio Paulista de Educação Física, realizado pelo Departamento de Educação Física do IB/UNESP Rio Claro, SP de 30/4 a 03/5 de 2009.

\section{Endereço:}

Vera Lícia de Souza Baruki

Rua Vitório Zeolla 436 Carandá Bosque I

Campo Grande MS Brasil

79.032-360

e-mail: vlbaruki@terra.com.br

Recebido em: 10 de fevereiro de 2009.

Aceito em: 03 de abril de 2009.

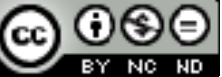

Motriz. Revista de Educação Física. UNESP, Rio Claro, SP, Brasil - elSSN: 1980-6574 - está licenciada sob Licenca Creative Commons 